OPEN ACCESS

Edited by:

Yu Zong Chen,

National University of

Singapore, Singapore

Reviewed by:

Ying Hong Li,

Chongqing University of Posts and

Telecommunications, China

Xiaoqiang Xiang,

Fudan University, China

Mariangela Garofalo,

University of Padova, Italy

*Correspondence:

Su Zeng

zengsu@zju.edu.cn

Specialty section

This article was submitted to Pharmacology of Anti-Cancer Drugs,

a section of the journal

Frontiers in Oncology

Received: 18 February 2020

Accepted: 16 April 2020

Published: 07 May 2020

Citation:

Qin Z, Xu Q, Hu H, Yu L and Zeng S (2020) Extracellular Vesicles in Renal Cell Carcinoma: Multifaceted Roles and Potential Applications Identified

by Experimental and Computational

Methods. Front. Oncol. 10:724.

doi: 10.3389/fonc.2020.00724

\section{Extracellular Vesicles in Renal Cell Carcinoma: Multifaceted Roles and Potential Applications Identified by Experimental and Computational Methods}

\author{
Zhiyuan Qin, Qingwen Xu, Haihong Hu, Lushan Yu and Su Zeng* \\ College of Pharmaceutical Sciences, Institute of Drug Metabolism and Pharmaceutical Analysis, Zhejiang University, \\ Hangzhou, China
}

Renal cell carcinoma (RCC) is the most common type of kidney cancer. Increasingly evidences indicate that extracellular vesicles (EVs) orchestrate multiple processes in tumorigenesis, metastasis, immune evasion, and drug response of RCC. EVs are lipid membrane-bound vesicles in nanometer size and secreted by almost all cell types into the extracellular milieu. A myriad of bioactive molecules such as RNA, DNA, protein, and lipid are able to be delivered via EVs for the intercellular communication. Hence, the abundant content of EVs is appealing reservoir for biomarker identification through computational analysis and experimental validation. EVs with excellent biocompatibility and biodistribution are natural platforms that can be engineered to offer achievable drug delivery strategies for RCC therapies. Moreover, the multifaceted roles of EVs in RCC progression also provide substantial targets and facilitate EVs-based drug discovery, which will be accelerated by using artificial intelligence approaches. In this review, we summarized the vital roles of EVs in occurrence, metastasis, immune evasion, and drug resistance of RCC. Furthermore, we also recapitulated and prospected the EVs-based potential applications in RCC, including biomarker identification, drug vehicle development as well as drug target discovery.

Keywords: renal cell carcinoma, extracellular vesicles, exosomes, biomarkers, drug targets, drug vehicles, artificial intelligence, machine learning

\section{INTRODUCTION}

Renal cell carcinoma, or RCC for short, is one of the most common type of urological cancers that represents $\sim 90 \%$ of all kidney malignancies (1). According to updated data provided by the World Health Organization, over 400,000 people were diagnosed with kidney cancer worldwide in 2018, accounting for nearly $3 \%$ of all cancers (2). It has been estimated that there will be about 74,000 new cases and 15,000 deaths associated with kidney cancer in the United States in 2020 (3). The 5-year survival rate among RCC patients increased for decades due to the improvement of early-detection techniques and targeted-therapies. The current overall 5-year survival rate of RCC is $75 \%$, decreasing to $70 \%$ among patients with regional metastases and $12 \%$ among patients with distant metastases (4). Still around one-third of patients diagnosed with RCC had metastases 
(5). The most common metastatic sites of RCC are lungs, bone, brain, lymph node, and liver might also be involved (6). Surgery is the mainstay curative treatment for localized RCC (7). However, around 40\% RCC patients will suffer tumor recurrence after curative surgical resection (8). For patients who present with metastatic RCC or relapses after local therapy, typically require systemic treatment. The current landscape of systemic therapies are consist of small molecule kinase inhibitors, cytokines, and monoclonal antibodies, including checkpoint inhibitors, which have been tested as first-line or second-line therapies (9).

Extracellular vesicles (EVs) are nanometer sized vesicles composed of a lipid bilayer membrane packaging a wealth of bioactive molecules such as RNA, DNA, protein, and lipid. Currently, EVs can be broadly divided into two main types based on the mechanism of biogenesis: one is exosomes which originate from the endosomal system and another one is microvesicles that directly shed from the plasma membrane (10). As Thery et al. mentioned in a review, both exosomes and microvesicles may be co-isolated due to the overlapping characteristics between these two forms of EVs and the limitations of current isolation methods. Therefore, the term exosomes is generally used in literatures to designate a mixed population of EVs without adequate characterization of the intracellular origin (11). Hereafter, we chose to use the generic term "EVs" in this review independent of the term used in the original articles.

With the nanoscale size and double-layered lipid membrane appropriately protecting the cargoes from degradation, EVs stably exist in blood, urine, saliva, and many other kinds of biological fluids. Accumulating evidences indicate that EVs traffic between donor and recipient cells are fundamental phenomenon of the intercellular information exchange, especially in tumor microenvironment (TME). EVs within TME are emerging as crucial contributor to carcinogenesis, angiogenesis, premetastatic niche (PMN) formation, dysfunction of immune system and the dissemination of anti-cancer drugs resistance, adding novel dimension to the complexity of TME (12). Thus, the contents of tumor-derived EVs may be applied as abundant sources to biomarker discovery identified by experimental and computational methods. In addition, EVs with naturally excellent biocompatibility and biodistribution are ideal materials to be exploited or engineered which may offer us achievable drug delivery strategies for cancer therapies (13). Furthermore, it is increasingly clear that mechanisms of EVs biogenesis, secretion and uptake could also provide promising targets for cancer therapy (14).

The past decades have witnessed unprecedented research progresses of EVs, especially for the roles of EVs in different malignant tumors. Nevertheless, to the best of our knowledge, few researchers paid close attention to the roles of EVs in urological malignancies, especially for RCC (15-22). There is still no comprehensive summary highlighting the EVs-based potential applications in RCC either. Hence, this review serves to introduce the latest research progresses in the burgeoning field of EVs, recapitulate the multifaceted functions of EVs in RCC progression. Accordingly, we will also give a perspective of the potential applications of EVs in RCC identified by both experimental and computational methods.

\section{BIOLOGICAL FEATURES OF EVS AND RESEARCH TECHNIQUES}

\section{Biogenesis, Secretion and Uptake of EVs}

The biogenesis of two EVs subtypes are different as shown in Figure 1. Diameter of microvesicles range from 50 to $1,000 \mathrm{~nm}$ but can up to $10 \mu \mathrm{m}$ in the case of oncosomes, which refers to cancer cells-derived microvesicles that contain oncogenic molecules $(10,23)$. Microvesicles are generated through the direct budding and fission of the cytoplasmic membrane then released into the extracellular space (24). Exosomes originate from multivesicular bodies (MVBs) within endosomal system, ranging from 30 to $150 \mathrm{~nm}$. The endosomal membrane invaginate intraluminal vesicles (ILVs) in the lumen during the mature process of early endosomes into late endosomes or MVBs. The endosomal sorting complex required for transport (ESCRT) machinery plays critical role in this process $(10,25)$. Moreover, members of the Rab GTPases family, including Rab27a/b, Rab11, and Rab35, are essential coordinators for MVBs trafficking and exosomes secretion $(26,27)$. The last step of secretion requires the fusion of MVBs with plasma membrane. This process primarily is mediated by soluble $N$-ethylmaleimidesensitive factor attachment protein receptors (SNAREs) and synaptotagmin family members to release ILVs as exosomes (28). Several studies have also found that $\mathrm{Ca}^{2+}$ may be involved in the activation of SNAREs $(29,30)$.

Once secreted into the extracellular milieu and absorbed by recipient cells, EVs cargoes can be transmitted to recipient cells to induce functional responses and confer new properties then result in phenotypic changes (10). This EVs-mediated interaction requires docking at the plasma membrane of recipient cells via several mediators such as clathrin, tetraspanins, and integrins to activate surface receptors and signaling pathways, being followed by vesicle endocytosis or membrane fusion of recipient cells (10, 31-33). The secretion processes of EVs are evolutionarily conserved among eukaryotes, bacteria, and archaea, which lay the foundation for interspecies transfer of genetic molecules via EVs (34). However, the whole process of exosomes biogenesis and secretion may be influenced by the heterogeneity of donor and recipient cells, different physiological or pathological conditions, making the detailed mechanisms remains elusive $(35,36)$.

\section{EVs Composition}

Diverse bioactive molecules such as RNA, DNA, proteins, and lipids can be packaged into EVs and secreted out of cell membrane at both local regional and systemic levels (37). A "routine passenger" of EVs is RNA. Both mRNA and microRNA (miRNA) could be loaded and transported through EVs then functioned in recipient cells (38-40). Besides, numerous long non-coding RNA (lncRNA) could also be transferred via EVs, inducing signals and phenotypes changes in a variety of cells in TME $(41,42)$. Furthermore, more than 1,000 circular RNA (circRNA) were identified in EVs derived from human serum. Interestingly, several circRNAs were highly enriched in EVs compared to the donor cells, which may provide more achievable applications in biomarker discovery $(43,44)$. Other RNA species were also detected in EVs by RNA deep sequencing analysis, 


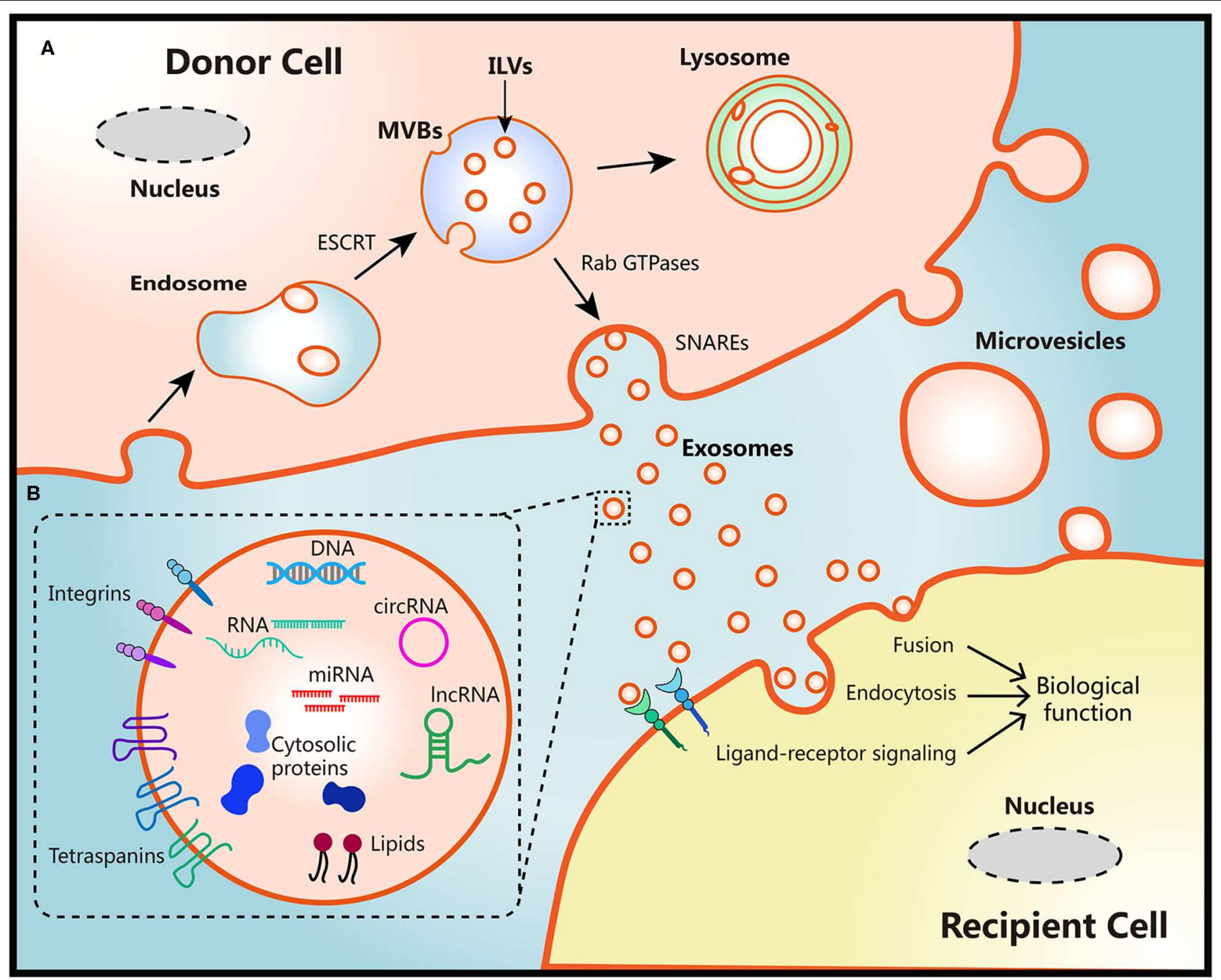

FIGURE 1 | Schematic diagram of the biological features of EVs. (A) Biogenesis, secretion and uptake of EVs. During the process of early endosome mature into MVBs, the endosomal membrane invaginate ILVs in the lumen of donor cells, which mediated by the ESCRT machinery. MVB fuse with cell surface and release ILVs as exosomes or degrade in lysosomes. Protein members of Rab GTPases, SNAREs, and synaptotagmin family play vital roles in MVBs trafficking and exosomes secretion. Microvesicles originate from the plasma membrane of donor cells directly. There are three ways to uptake EVs and induce biological functions in recipient cells: fusion with membrane of recipient cells directly, internalization by endocytosis, or activation of ligand-receptor signaling. (B) Representative structure and composition of EVs. EVs are nanometer sized vesicles composed of a lipid bilayer membrane. Size of exosomes range from 30 to $150 \mathrm{~nm}$, Diameter of microvesicles range from 50 to $1,000 \mathrm{~nm}$ but can up to $10 \mu \mathrm{m}$ in the case of oncosomes. EVs package various bioactive molecules such as RNA, DNA, proteins, and lipids. Transmembrane including integrins and tetraspanins are also contained in EVs.

including transfer RNA, ribosomal RNA and piwi-interacting RNA $(44,45)$.

The presence of DNA within EVs also provide novel insights into the cellular homeostasis and open another intriguing mode of intracellular communication (46). It has been reported that EVs secretion removed various length of chromosomal DNA fragments which were harmful to normal human cells (47). Moreover, studies demonstrated that retrotransposon elements, oncogene amplifications, and other functional DNA fragments that reflected the genetic status of the parent tumor cells were found in EVs $(48,49)$. Notably, these transposable elements could be encapsulated and transferred from tumor cells to normal cells (50). Thereby it can be inferred that tumor-derived EVs may function as novel mediators of horizontal gene transfer and make contribution to tumor evolution in local or systematical level (51).

As a consequence of the biogenesis, EVs derived from different cell types contain substantial cytosolic proteins, such as Rab GTPase, SNAREs, and Annexins (52). Tetraspanins is a highly conserved family of transmembrane proteins which have been found in EVs from diverse cell types. It is believed that tetraspanins interact or coordinate with other proteins and involve in membrane compartmentalization (53). Members of this family, including CD9, CD63, and CD81, consist part of 
the most abundant proteins in EVs, thus commonly be used as protein markers for EVs characterization (54). In addition, increasing evidences have demonstrated the presence of several transporters and enzymes in EVs with full activity (55-57). Thus, it can be inferred that the change of EVs components can be connected with the in vivo fate of drugs.

\section{EVs Isolation and Characterization}

Since research field of EVs has achieved high-speed development in the past few decades, many techniques have been used to isolate and characterize EVs. At present, the frequently used techniques for EVs isolation can be summarized into five broad categories: differential ultracentrifugation (UC), polymer-based precipitation, particle size-based techniques, immunological capture, and microfluidic techniques (58). As one of the most traditionally and widely used method, differential UC is suitable for most sources of EVs, even though it is laborious, timeconsuming, and inaccessible. Several commercial isolation kits are developed based on above theories and techniques to isolate EVs more efficiently and precisely. However, according to results of a recent benchmark study, a large quantity of non-vesicular contaminants may be co-isolated by these kits. While the purity of EVs isolated by differential UC was much higher than commercial kits (59). More recently, microfluidicbased platforms have generated heightened interest. Based on specific capture of the surface marker or the specific size and density of EVs subsets, microfluidic-based platform can provide advantages such as low consumption, ready portability, with high throughput, and high precision (60). Since there is still no consensus on a "gold standard" method for EVs isolation and purification, comparison study is still needed to analyze the parameters of EVs isolated by different methods. According to a global survey in 2015 conducted by the International Society for Extracellular Vesicles (ISEV), around $81 \%$ of respondents chose differential UC as their primary isolation method, around 59\% of respondents used a combination methods of differential UC with other techniques (61). In terms of EVs characterization, multiple techniques based on biophysics and molecular biology have been developed and applied. Three of the most common methods are western blotting for identification of specific protein marker, electron microscopy for detection of structural information and nanoparticle tracking analysis for quantification of EVs size and concentration, respectively. Generally speaking, two or more complementary methods are necessary to assess the results of separation methods as ISEV recommended (62).

\section{ROLES OF EVS IN RCC}

EVs is employed by tumor cells to deliver bioactive molecules directing to not only tumor cells but also tumor-associated cells including fibroblasts, endothelial cells, immune cells, and cancer stem cells (CSCs) $(63,64)$. Reciprocally, EVs derived from non-tumor cells also have influence on tumor progression in TME. Therefore, these multidirectional communications via EVs make TME becoming a more complex network, which draw accumulating attention of researchers in recent years. Herein we reviewed the latest studies about roles of EVs in carcinogenesis, cancer metastasis, immune evasion, and drug resistance of RCC (Figure 2).

\section{Tumorigenesis}

EVs secreted by different cells in TME may make contributions to RCC progression and development. Jiang et al. revealed that EVs secreted by RCC cell line OS-RC-2 could inhibit hepaCAM expression, a tumor suppressor frequently lost in various types of human cancers, and promote cell proliferation in a p-AKT-dependent pathway (65). By use of cell culture and nude mice xenograft model, Du et al. claimed that EVs released by human Wharton's jelly mesenchymal stem cells induced HGF expression, activated AKT and ERK1/2 signaling pathways, then promoted the proliferation and aggressiveness of RCC cells both in vitro and in vivo (66). By using next-generation sequencing, Song et al. found the levels of EVs-contained miR-30c-5p in RCC cell lines 786-O and ACHN were significant lower than that in human renal proximal tubular cell line HK-2. Consistently, the expression pattern of miR-30c-5p was significant different in urinary EVs from healthy controls and patients of clear cell RCC (ccRCC), which is the predominant RCC type. Heat-shock protein 5 was identified as a direct target of miR-30c-5p. Gainof-function study showed that overexpression of miR-30c-5p inhibited ccRCC progression both in vitro and in vivo (67). Considered together, these data suggest that EVs may transfer various cargoes between heterogeneous cells within TME, initiate the critical regulation of the tumorigenesis to support the growth of RCC cells.

Hypoxia is one of the distinguishing features of TME in many solid tumors including RCC. Carbonic anhydrase IX (CAIX), a cellular hypoxia biomarker that overexpress in RCC with von Hippel-Lindau (VHL) gene mutation, is involved in proliferation and transformation of RCC cells (68). It has been revealed that abundant CAIX proteins were detected in EVs released from RCC cell lines. Result of in vitro angiogenesis assays demonstrated that hypoxic RCC cells could release EVs containing CAIX and promote the migration and tube formation abilities of human umbilical vein endothelial cells (69). Several researchers have also provided direct evidences that hypoxia not only regulated the tumorigenic potential of epithelial cells, but also contributed to EVs production of tumor cells in response to low $\mathrm{pH}$ and oxidative stress $(70,71)$. Wang et al. reported that acute hypoxia condition induced by $\mathrm{CoCl}_{2}$ treatment upregulated miR-210 expression in EVs which derived from both normal renal cells and RCC cells, especially for metastatic RCC cell line (72). Interestingly, EVs secreted by hypoxic cells are more easily absorbed by hypoxic cells (73). Hitherto, there is limited knowledge about the mechanism of how hypoxia orchestrate the biogenesis and secretion of EVs. Nevertheless, it can be concluded that hypoxia-induced EVs derived from stromal and tumor cells are crucial mediator in the process of tumorigenesis and TME rebuilding.

\section{Tumor Metastasis}

Recent years, numerous investigations have revealed the significant influence of EVs on both regional and distant metastatic processes, including coagulation, vascular leakiness, 


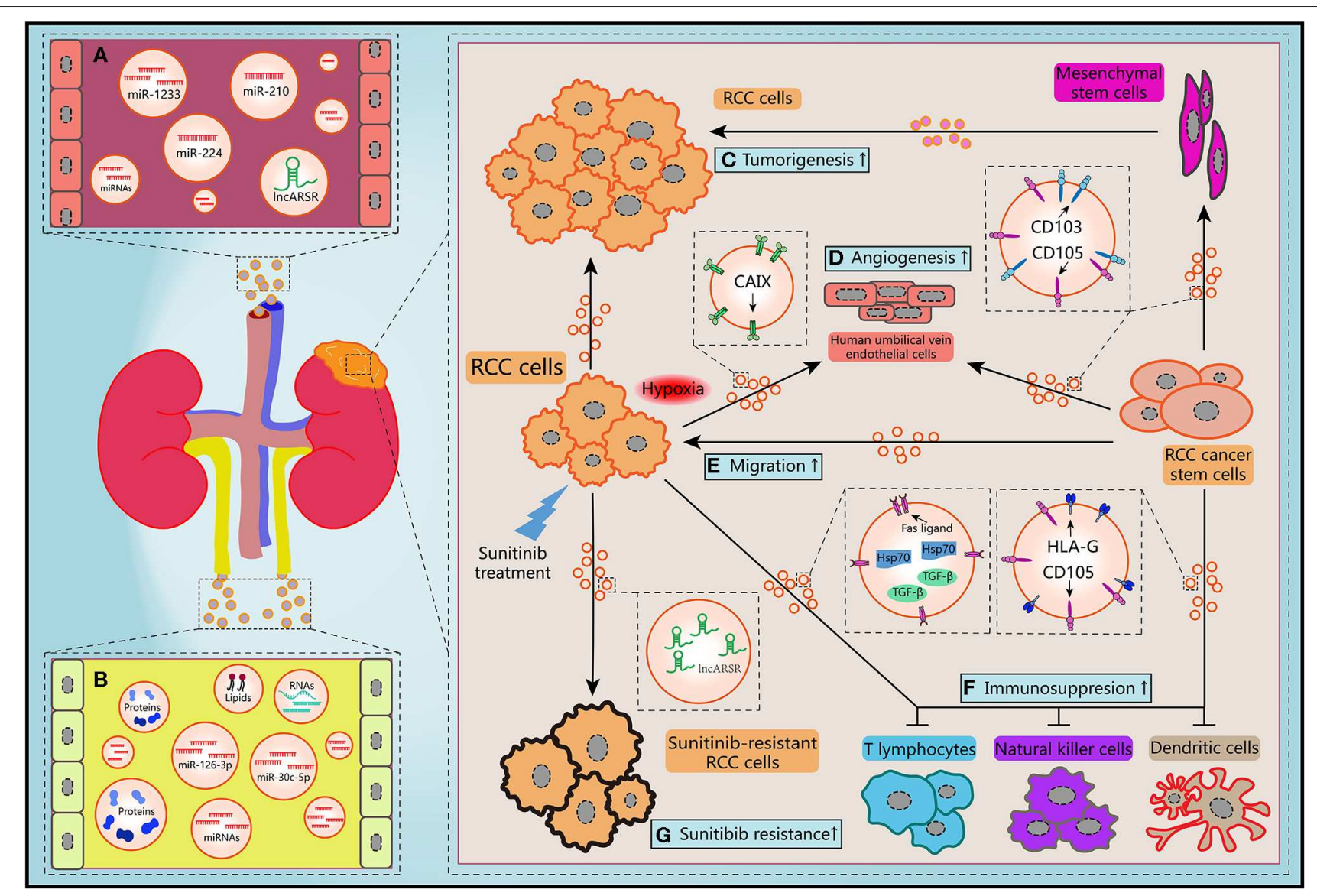

FIGURE 2 | Schematic diagram of the biological features of EVs. (A) Circulating EVs in blood contain potential biomarkers of RCC. (B) Circulating EVs in urine contain potential biomarkers of RCC. (C) RCC-derived EVs and mesenchymal stem cells-derived EVs promoted the tumorigenesis of RCC cells. (D,E) Migration ability of RCC cells and angiogenesis of human umbilical vein endothelial cells and could be improved by hypoxic RCC cells released EVs containing CAIX, CD103-positive or CD105-positive RCC CSCs-derived EVs. (F) RCC cells-derived EVs and RCC CSCs-derived EVs facilitated the immunosuppression of immune cells. (G) Sunitinib treatment induced RCC cells secreted EVs delivering IncARSR to increase the drug resistance of RCC cells.

reprogram of stromal recipient cells, and formation of PMN (74). However, the roles of EVs in RCC metastasis are still need to be unraveled. It has been shown that MMP-9 and CXCR-4 are closely associate with tumor metastasis and highly express in different cancer types. Chen et al. revealed that expression levels of these two proteins were upregulated after co-cultured RCC cell line 786-O with EVs shed from itself, which resulted in the improvements of the migration and invasion abilities and suppression of the adhesion ability (75). Camussi's team identified a subset of tumor-initiating cells expressing mesenchymal stem cell marker CD105 from human RCC specimens in a previous work. They found that EVs released by renal $\mathrm{CD} 105^{+} \mathrm{CSCs}$ could trigger angiogenesis both in vitro and in vivo, and enhanced the lung metastases induced by injection of renal tumor cells intravenously. Furthermore, mRNAs and miRNAs implicating in tumor progression and metastasis were identified through molecular characterization of EVs (76). Subsequently, Camussi et al. reported that renal CSCsderived EVs could stimulate persistent phenotypical changes in mesenchymal stem cells in vitro and support the tumor growth and vascularization when co-injected with RCC cells in vivo (77). Their conclusions unveiled that EVs shed from a subtype of renal CSCs may play critical roles in the TME modification, PMN formation, and metastasis of RCC in lung, which is one of the most common site of RCC metastasis.

Recently, Wang et al. demonstrated that $\mathrm{CD}_{103^{+}} \mathrm{CSCs}$, another subtype of renal CSCs, could release EVs enwrapping miR-19b-3p and deliver to RCC cells to initiate epithelialmesenchymal transition (EMT) via suppressing the expression of PTEN. Quantitative detection of expression changes of EMT markers such as $\mathrm{N}$-cadherin, Vimentin and Twist showed that $\mathrm{CD}_{103}{ }^{+} \mathrm{CSCs}$ EVs derived from RCC patients with lung metastasis presented significant effects on EMT. Notably, results of flow cytometry quantification also showed that the ratio of $\mathrm{CD}_{103}{ }^{+}$EVs over total EVs was higher in blood samples of RCC patients with lung metastasis than non-metastasis patients (78). Therefore, it can be inferred that EVs-contained CD103 may be involved in the organotropism of RCC. Additionally, previous work suggested that tetraspanins and integrins were also associated with metastasis organotropism $(79,80)$. Typically, 
integrins $\alpha_{6}$ and $\alpha_{\mathrm{v}}$ were closely relevant to lung and liver metastases, respectively (33). Since lung and liver are common sites for RCC metastasis, we can believe that integrins $\alpha_{6}$ and $\alpha_{\mathrm{V}}$ may present in RCC-derived EVs and address these EVs to specific organs. Hence these endogenous surface molecules of EVs provide us crucial clues to understand the complex mechanism of tumor metastasis. It will be promising to develop indicators of metastatic prognosis and selective target-binding therapeutics for RCC treatment through unraveling the functions these transmembrane proteins.

\section{Immune Evasion}

In the past decade, the deep comprehension of communication between the immune cells and malignant tumor cells in TME has become a popular research field. Emerging investigations advocated that EVs are active players in this scenario (81). However, this interaction can be hijacked by tumor cells to facilitate immune evasion and stick many anti-cancer therapeutic strategies. Studies showed that the activation of T cells and the differentiation processes of monocytes to dendritic cells (DC cells) were both impaired by EVs derived from renal CD105 ${ }^{+}$ CSCs (82). This immune inhibitory effect was mediated by HLA$\mathrm{G}$, an antigen highly overexpressing in RCC and facilitating to immunosuppression (83). HLA-G blockade markedly relieved the inhibitory effect of EVs on DC cells differentiation. It has also been verified that EVs purified from RCC cell line ACHN contained Fas ligand and contributed to apoptosis of Jurkat $\mathrm{T}$ lymphocyte and immune evasion of RCC cells. These effects could be rescued by soluble Fas treatment (84). Natural killer (NK) cells are crucial player in the innate immune system, possessing strong abilities to control and kill tumor cells. Xia et al. found that EVs derived from primary RCC cells contained TGF- $\beta$, a major immunosuppressive cytokine. Co-culturing these EVs with NK cells exacerbated the dysfunctions of NK cells in a TGF- $\beta / S M A D$-dependent manner (85). Furthermore, Diao et al. elucidated that Hsp70 protein was more enriched in EVs than that in whole-cell lysates of Renca cells which is a cancer cell line of murine kidney. EVs-contained Hsp70 triggered the phosphorylation of Stat3 through regulating TLR2-MyD88 pathway and impeding the activity of the myeloid-derived suppressor cells (86). Considered together, these conclusions suggest that RCC cells may secrete EVs to interfere the immune system and support evasion of innate immune surveillance. Potential drug targets or biomarkers of the immunotherapy can be developed by clarifying the detailed mechanism of intercellular communication between cancer cells and immune cells.

Immunotherapy is one of the most promising therapeutic approach in multiple cancer types including RCC. Immune checkpoint protein inhibitors, especially antibodies against programmed cell death-1 (PD-1) and its ligand programmed death-ligand 1 (PD-L1), have elicited anti-cancer effects and long-lasting alleviation in melanoma, lymphoma, bladder cancer, non-small-cell lung cancer, RCC, and many other malignancies (87). However, only limited subset of patients exhibited durable response to immunotherapies. The total respond rate of antiPD-1/PD-L1 therapy is merely around $10-30 \%$ (88). Previous studies have identified EVs-contained PD-L1 in diverse sources, including plasma of head and neck cancer glioblastoma, and melanoma patients as well as culture medium of breast cancer cell lines (89-94). A recent work demonstrated that EVs could support tumor growth by carrying PD-L1 and suppressing $\mathrm{T}$ cell activation in draining lymph nodes. Genetic blockade of EVs-contained PD-L1 induced long-term and systemic antitumor effects (95). Most recently, several novel methods were developed to quantitate the PD-L1 level in EVs. These newly approaches were higher in sensitivity, time-saving, and easily operated compared with ELISA-based canonical methods (96, 97). However, to the best of our knowledge, yet still no research focus on the PD-L1 in RCC-derived EVs. Above findings enlighten us that inhibition of EVs-contained PD-L1 may be an alternative therapy for RCC treatment, especially for RCC patients that are resistant to anti-PD-L1 antibodies. Meanwhile, EVs-carried molecules represented by PD-L1 may serve as reliable biomarkers for immunotherapies.

\section{Drug Resistance}

Accumulating evidences corroborate that EVs make nonnegligible contributions to the resistance of anti-cancer drugs. The horizontally intercellular transmit of drug resistance are mediated by EVs cargoes including drug-efflux transporters, miRNAs, lncRNAs (98). Corcoran et al. established and characterized docetaxel-resistant variants of two prostate cancer cell lines by a serial assays including cross-resistance, morphology, multi-category phenotypes, and EVs secretion. They revealed that EVs released from docetaxel-resistant prostate cancer cells subverted sensitive cells to docetaxelresistant phenotype through the involvement of EVs delivering multidrug resistance protein 1 . Consistent results were presented when co-cultured docetaxel-sensitive prostate cancer cells with serum-derived EVs from prostate cancer patients before and after commencing docetaxel treatment (99). As a vital organ for the elimination and reabsorption of therapeutic drugs, kidney contain various drug transporters in proximal tubules. Thereby the variability of renal drug transporters will impact the processes of drug disposition (100). However, there is still no study focus on the drug resistance in RCC mediated by EVs-contained drug transporters.

Since several receptor tyrosine kinases relevant to angiogenesis and homeostasis of TME are overexpressed predominantly due to inactivation of VHL gene in ccRCC, inhibitors targeted receptor tyrosine kinases such as sunitinib have become the one of first-line therapies for RCC treatment (101). However, the clinical benefit of sunitinib treatment in ccRCC patients is limited due to inherent or acquired resistance. As such, the biological basis for resistance to sunitinib therapy and the clinical approach in this setting is of heightened interest of investigators (102). Qu et al. obtained sunitinib-resistant RCC cells through cycles of sunitinib treatment to nude mice with serial xenografts. Then lncRNA required for sunitinib resistance in RCC was identified by three rounds of screening sequentially. Firstly, lncRNA expression profiles between parental and sunitinib-resistant RCC cells was compared by lncRNA microarray. Then they established patient-derived xenograft models of RCC and mimic sunitinib therapy. Eight 
IncRNA candidates were consequently selected to loss-offunction analysis by RNAi in sunitinib-resistant RCC cells. LncARSR was eventually identified as a highly abundant lncRNA in sunitinib-resistant ccRCC cells, which could favor sunitinib resistance via competitively binding both miR-34 and miR-449 to improve AXL and c-MET expression. More interestingly, IncARSR could be secreted and delivered via EVs to transform the phenotype of recipient cells from sunitinib-sensitive to sunitinib-resistant and lead to the dissemination of sunitinib resistance (103). Overall, it is valuable to clarify the various mechanisms of anti-cancer drugs resistance mediated by EVs, which may further help us to identify desirable biomarkers that can be used in drug response and identify novel targets to restore therapeutic approaches.

\section{CLINICAL IMPLICATIONS OF EVS IN RCC}

Recent years, many reviews have summarized the clinical implications of EVs in a variety of cancer types. Since the composition of the original cells can be reflected in the cargoes of EVs in a real-time mode, the initial interest of clinical implications is to find vital biomarkers from this favorable reservoir. EVs are natural nanoscale vesicles as ideal engineering platform owing to their unique advantages such as low toxicity and long-term stability in biofluids (104). EVs-based drug target discovery is also draw considerable attention of researchers due to recent findings. Moreover, RCC is still a malignant tumor with unpredictable progression, limited effective therapies and poor clinical prognosis. The progresses of clinical application of EVs in RCC is also relatively lag behind than that in other cancer types. Accordingly, the demonstrated and conceivable clinical implications of EVs in RCC will be discussed here from following aspects.

\section{EVs-Derived Biomarkers for RCC}

Owing to the encapsulation by vesicle membrane, the bioactive molecules within EVs are free from degradation by exogenous nucleases or proteases and stable in biological fluids (15). These abundant content which may be reliable biomarkers for prediction of RCC progression have been extensively investigated. Previously, Zhao et al. reported that the expression level of miR-210 was differentially higher in primary RCC tissues of 32 patients than non-tumor renal parenchymas. Results of receiver operating characteristic (ROC) analysis also showed that ccRCC patients and healthy individuals could be discriminated by the average level of cell-free miR-210 in serum (105). They assessed expression levels of three miRNAs (miR-210, miR-1233, and miR-15a) in serum-derived EVs in a follow-up work. Results of ROC analysis showed that it was feasible to use miR-210 and miR-1233 but not miR-15a as diagnostic biomarkers (106). Consistently, a recent study confirmed the expression level of miR-210 in serum-derived EVs was significantly higher in RCC patients than healthy controls (72). Similarly, expression level of miR-224 was also overexpressed in cancer tissues of ccRCC patients $(107,108)$. The level of serum EVs-contained miR-224 was significantly correlated with progression-free survival (PFS) or overall survival (OS) of ccRCC patients (109). Moreover, a study evaluated the possibility of miRNAs from plasma-derived EVs for RCC prognosis by RNA sequencing. Results of KaplanMeier analysis confirmed the correlations of three miRNAs with OS of RCC patients, including miR-let-7i-5p, miR-26a-1-3p, and miR-615-3p (110).

Urine as a dynamic biofluid is also a promising source for RCC biomarker development rather than a waste product of body. Urinary EVs can be released from every renal epithelial cell type facing the urinary tract. Therefore, the cargoes of urinary EVs may be accessibly real-time signals for renal dysfunction. However, only few researchers attempted to find bioactive molecules from urinary EVs and these snapshots need to be further characterized (18). Study reported that combinations of urinary EVs-derived miRNAs (miR-449a, miR-34b-5p, or miR-486-5p with miR-126-3p) had the power to distinguish healthy controls, patients with benign renal tumors, and patients with early-stage or advanced ccRCC (111). It has also claimed that the level of miR-30c-5p within the urinary EVs was significantly decreased in ccRCC patients but not in other urological malignancies samples (67). In addition, differential levels of miR-150 and miR-205 were found in EVs isolated from 786-O and HK-2 cell lines (112). Our previous work showed that the lost expression of organic cation transporter 2 were partly due to the downregulation by miR-489-3p and miR-630. Interestingly, miR-489-3p and miR-630 were more abundant in EVs than donor cells $(113,114)$. Therefore, these findings of fundamental work may also have translational value to provide clues for RCC biomarker discovery in a certain extent.

In addition to miRNAs, other content of EVs also have potential to be developed as biomarkers for RCC. As mentioned above, lncARSR was elucidated as a mediator of the transmission of sunitinib resistance, which could be enwrapped and delivered through EVs. Qu et al. further revealed that circulating lncARSR could be utilized as indicator to predict sunitinib response in RCC patients (103). Moreover, Palma et al. reported that the mRNA levels of GSTA1, CEBPA, and PCBD1 genes in urinary EVs were lower in RCC patients than that in control subjects and this pattern backed to normal level after 1 month of nephrectomy (115). In 2012, Boccio et al. established a hyphenated micro LCQ-TOF-MS platform to profile the lipid repertoire of human urinary EVs. A comparative analysis for lipid content in urinary EVs purified from RCC patients and healthy subjects was performed for the first time (116). Similarly, a proteomics study in 2013 reported that the protein composition of urinary EVs was substantially different in RCC patients and control subjects. Results presented for the first time that considerable number of proteins were significantly enriched in RCC patients, including Ceruloplasmin, Podocalyxin, Dickkopf related protein 4, MMP9 and CAIX (117). A recent work reported that Azurocidin was highly enriched in EVs isolated from tumor tissues of ccRCC patients than adjacent normal tissues. Importantly, Azurocidin content was also significantly higher in serum EVs from ccRCC patients compared to healthy controls (118). These tentative work provided valuable indications for exploiting potential mRNA, lipid, and protein biomarker for RCC from urinary EVs. Taken together, it can be concluded that multiple EVs cargoes derived from different kinds of biofluids are promising 
non-invasive biomarkers for early diagnosis and treatment of RCC. The potential biomarkers derived from EVs which have been validated in clinical samples of RCC are listed in Table $\mathbf{1}$.

\section{EVs-Based Drug Vehicles and Targets in RCC}

The biological characteristics make EVs can be harnessed as vehicles for therapeutic agents to improve curative effect. Numerous clinical and preclinical trials have suggested that these EVs-based drug vehicles and therapies are promising, feasible and well-tolerated (119-121). There are two basic approaches to load cargoes into EVs: exogenous loading and endogenous loading. Exogenous modification can be achieved after collection of EVs, with encapsulation of small molecules, proteins, and RNAs into or onto EVs via diverse methods including coincubation, electroporation, and sonication (121). Tian et al., developed a tumor-targeting EVs from mouse immature DC cells expressing a well-characterized EVs membrane protein (Lamp2b) fused to integrin $\alpha_{\mathrm{v}}$-specific iRGD, which is a new tumor-homing and penetrating peptide. After loaded with doxorubicin via electroporation, this delivery platform showed high efficiency in tumor-targeting and doxorubicin delivery to integrin $\alpha_{\mathrm{v}}$-positive breast cancer cells both in vitro and in vivo (122). Wan et al. developed a nucleolin-targeting aptamer AS1411 which covalently conjugated to cholesterol-PEG and anchored onto membrane of mouse DC cells. Subsequently, EVs were obtained from this modified DC cell model and loaded with paclitaxel by sonication. Results of cancer treatment in xenograft nude mice showed that engineered EVs enhanced therapeutic efficacy with low systemic toxicity (123). We can believe that along with the detailed mechanism of EVs-mediated metastasis organotropism are being clarified, EVs are promising material to achieve drug-targeting delivery for cancer treatment. However, the immune responses are need to be considered seriously. Additionally, the production yield is also a challenge for applying engineered EVs in tumor-targeting delivery.

Alternatively, cargo of EVs can be endogenously loaded through genetically manipulating the donor cells to overexpress bioactive molecules and employed as EVs-based vaccines or imaging tools. With significant higher level in surface of RCC cells than normal renal cells, RCC-associated antigen G250 could be served as one of the therapeutic targets (124). EVs containing G250 or other RCC-specific antigens may be novel approaches to develop EVs-based cancer vaccines for RCC treatment. It has been shown that modified RCC cells released EVs expressing both glycolipid-anchored-IL-12 and G250, which efficiently promoted the proliferation of antigen-specific cytotoxic T lymphocytes and enhanced cytotoxic effects (125). Notably, there is a risk of mixing pathogens such as viruses with EVs since these nanometric vesicles have similar biophysical properties (126). Hence a standard operating procedure is very necessary when isolate EVs as cancer vaccine. By combining a Cre recombinase-based system with high-resolution fluorescence imaging techniques, Zomer et al. realized the visualization of intracellular EVs exchange within local and distant tumor sites in vivo. Results showed that less malignant tumor cells presented heightened migratory ability after taken up the EVs released by highly malignant tumor cells (127). Moreover, several other molecular imaging strategies have also been utilized to monitor and determine the biodistribution of EVs in vivo, including bioluminescence, nuclear, and magnetic resonance imaging techniques (128). These interesting findings and advanced techniques make it clear that EVs-based modification can be used to achieve the phenocopying of tumor cells and visualize cancer development process in vivo in the future.

Drugs targeting vital steps in formation, release or uptake of EVs may also be served as effective adjuvants for cancer treatment. Datta et al. utilized quantitative high throughput screen assay to find active compounds targeting the formation and release of EVs in prostate cancer cells. Totally five and six lead compounds were validated as potent inhibitors and activators, respectively (129). In another review, two groups of candidate drugs were broadly classified according to the mechanisms of modulating EVs biogenesis or secretion. One is compounds that specifically inhibit EVs trafficking, including calpeptin, manumycin A, and Y27632. Another group is compounds that specifically disrupt lipid metabolism, including pantethine, imipramine, and GW4869 (130). Interestingly, Ortiz et al. identified that reserpine, a commonly used anti-hypertensive drug since 1955, could alter the fusion process of lipid membrane and then inhibit PMN formation that was induced by melanomaderived EVs. Their findings indicated that tumor-derived EVs could "educate" healthy cells to facilitate tumor metastasis. Meanwhile agents like reserpine can interfere this education process and play a defensive role on EVs uptake. Thus, it is valuable to repurpose these drugs as adjuvant treatment for metastatic cancer therapy (131). More recently, sulfisoxazole, an oral antibacterial drug approved by US FDA, was screened out as inhibitor of EVs secretion in breast cancer cells. Through targeting endothelin receptor $\mathrm{A}$, sulfisoxazole promoted the degradation of ESCRT-dependent MVB, suppressed biogenesis and secretion of EVs, as well as significantly inhibited the growth and metastasis of breast cancer cells without notable toxicity (132). These important findings enlighten us drug repurposing can be harnessed as approaches to block EVs functions in tumor progression.

\section{Potential Application of Artificial Intelligence in EVs Research}

Artificial intelligence (AI) refers to the simulation of human intelligence in machines. AI approaches have the potential to enhance the qualitative interpretation of cancer imaging by expert clinicians in three main tasks: computer-aided detection of tumor sites, characterization of intra-tumor heterogeneity and variation, as well as temporal monitoring of tumor changes (133). As a specific subset of AI approaches, machine learning (ML) are able to interpret complex data and leverage the detailed information to make accurate prediction or decision. Studies have demonstrated that deep learning frameworks can be applied to distinguish major subtypes of RCC using histological or computed tomography images $(134,135)$. Similarly, ML algorithms also have the power to analyze a substantial 
TABLE 1 | EVs derived potential biomarkers with clinical significance for RCC.

\begin{tabular}{|c|c|c|c|c|c|c|c|}
\hline Type & $\begin{array}{l}\text { EVs } \\
\text { source }\end{array}$ & EVs cargoes & Analysis method & Cohorts & Clinical significance & Year & References \\
\hline Lipid & Urine & $\begin{array}{l}\text { LysoPE etc. } 196 \\
\text { differential signals }\end{array}$ & $\begin{array}{l}\text { microLC-Q-TOF- } \\
\text { MS }\end{array}$ & $\begin{array}{l}8 \text { ccRCC patients, } 8 \\
\text { HS }\end{array}$ & $\begin{array}{l}48 \text { differential lipidomes ( } 22 \text { upregulated } \\
\text { and } 26 \text { downregulated in RCC) }\end{array}$ & 2012 & (116) \\
\hline IncRNA & Plasma & Circulating IncARSR & qRT-PCR & $\begin{array}{l}71 \text { advanced ccRCC } \\
\text { patients, } 32 \mathrm{HS}\end{array}$ & $\begin{array}{l}\text { Differentiated ccRCC patients from healthy } \\
\text { controls; High IncARSR levels in } \\
\text { pre-therapy correlated with PFS } \\
\text { independent of clinical characteristics }\end{array}$ & 2016 & (103) \\
\hline \multirow[t]{6}{*}{ miRNA } & Plasma & $\begin{array}{l}\text { miR-let-7i-5p, } \\
\text { miR-26a-1-3p, } \\
\text { miR-615-3p }\end{array}$ & $\begin{array}{l}\text { RNA-sequencing, } \\
\text { qRT-PCR }\end{array}$ & $\begin{array}{l}44 \text { and } 65 \text { metastatic } \\
\text { RCC patients for } \\
\text { screening and validate } \\
\text { cohort, respectively }\end{array}$ & $\begin{array}{l}\text { Low levels correlated with poor OS of } \\
\text { mRCC patients, independent of age, } \\
\text { gender, tumor grade, stage at diagnosis, } \\
\text { coagulative necrosis, or sarcomatoid } \\
\text { differentiation }\end{array}$ & 2017 & (110) \\
\hline & Serum & $\mathrm{miR}-210$ & $\begin{array}{l}\text { Microarray, } \\
\text { qRT-PCR }\end{array}$ & $\begin{array}{l}45 \text { pre-operative and } \\
35 \text { post-operative } \\
\text { ccRCC patients, } 30 \mathrm{HS}\end{array}$ & $\begin{array}{l}\text { Significant higher in ccRCC patients than } \\
\text { HS, and in pre-operative than } \\
\text { post-operative samples }\end{array}$ & 2019 & (72) \\
\hline & Serum & miR-224 & qRT-PCR & 108 ccRCC patients & $\begin{array}{l}\text { High level correlated with shorter PFS, } \\
\text { CSS and OS of CCRCC patients }\end{array}$ & 2017 & (109) \\
\hline & Urine & miR-126-3p & $\begin{array}{l}\text { Microarray, } \\
\text { qRT-PCR }\end{array}$ & $\begin{array}{l}81 \text { ccRCC patients, } 33 \\
\text { HS }\end{array}$ & Differentiated ccRCC patients from HS & 2016 & (111) \\
\hline & Urine & $\begin{array}{l}\text { miR-126-3p combined } \\
\text { miR-449a }\end{array}$ & $\begin{array}{l}\text { Microarray, } \\
\text { qRT-PCR }\end{array}$ & $\begin{array}{l}81 \text { ccRCC patients, } 33 \\
\text { HS }\end{array}$ & Differentiated ccRCC patients from HS & & \\
\hline & Urine & $\begin{array}{l}\text { miR-126-3p combined } \\
\text { miR-34b-5p }\end{array}$ & $\begin{array}{l}\text { Microarray, } \\
\text { qRT-PCR }\end{array}$ & $\begin{array}{l}81 \text { ccRCC patients, } 33 \\
\text { HS }\end{array}$ & $\begin{array}{l}\text { Differentiated ccRCC and small renal } \\
\text { masses }(\mathrm{pT} 1 \mathrm{a}, \leq 4 \mathrm{~cm} \text { ) patients from } \mathrm{HS} \text {, } \\
\text { respectively }\end{array}$ & & \\
\hline \multirow{4}{*}{ Protein } & Urine & $\begin{array}{l}\text { Aquaporin-1, } \\
\text { Extracellular matrix } \\
\text { metalloproteinase } \\
\text { inducer, Neprilysin, } \\
\text { Dipeptidase 1, } \\
\text { Syntenin-1 }\end{array}$ & $\begin{array}{l}\text { LC-MS/MS, } \\
\text { western blotting }\end{array}$ & $\begin{array}{l}9 \text { ccRCC patients, } 9 \\
\text { HS }\end{array}$ & $\begin{array}{l}\text { Significant lower in ccRCC patients than } \\
\text { HS }\end{array}$ & & \\
\hline & Serum & CD103 & Flow cytometry & $\begin{array}{l}76 \text { and } 133 \text { metastatic } \\
\text { or non-metastatic } \\
\text { ccRCC patients, } \\
\text { respectively }\end{array}$ & $\begin{array}{l}\text { Higher ratio of } \mathrm{CD} 103^{+} \mathrm{EV} \text { s over total EVs } \\
\text { in samples of metastatic patients than } \\
\text { non-metastatic patients }\end{array}$ & 2019 & (78) \\
\hline & Serum & Azurocidin & LC-MS/MS & $\begin{array}{l}19 \text { ccRCC patients, } 10 \\
\text { HS }\end{array}$ & $\begin{array}{l}\text { Significant higher in ccRCC patients than } \\
\text { HS }\end{array}$ & 2018 & (118) \\
\hline & Tissue & Azurocidin & LC-MS/MS & $\begin{array}{l}20 \text { paired tumor and } \\
\text { adjacent normal tissues } \\
\text { of cCRCC patients }\end{array}$ & $\begin{array}{l}\text { Significant higher in ccRCC patients than } \\
\text { HS }\end{array}$ & & \\
\hline
\end{tabular}

amount of images that are produced by EVs purification and characterization processes. Studies showed that these biophysical parameters of EVs could be assessed by ML algorithms to identify the subpopulation of EVs or even further predict the original donor cells $(136,137)$. Due to the incredible amount of EVs and the need for downstream analysis during 
each study, multiparameter results of EVs characterization are particularly amenable to ML algorithms. A preliminary work of Borgovan et al. reported that ML algorithms could distinguish the heterogeneous EVs derived from blood samples with healthy or leukemic phenotypes based on data sets collected from a nanoparticle tracking analysis, thus improved the accurate of EVs classification (138).

At present, one of the most challenges in the field of biomarker discovery is how to decipher the huge amount of garbled information within EVs. AI approaches are becoming trustworthy solutions to this given problem as they are able to modelize complicated network and leverage valuable information within observed data to accurately estimate and predict new samples. Early in 2003, Won et al. had identified five protein biomarkers of serum by using a mass spectrometry-based protein profiling and AI analysis and then successfully differentiated RCC from healthy subjects and other urological diseases (139). Moreover, Zheng et al. developed a novel diagnosis tool to predict early-stage RCC patients which depended on a biomarker cluster that was identified by serum metabolomics method and ML algorithms (140). Meanwhile, unprecedentedly massive data of EVs are also being generated by various "omics" technologies including genomics, transcriptomics, proteomics, metabolomics, glycomics, and lipidomics (141). Several online databases have been established to categorize the RNAs, lipids, proteins, and metabolites within EVs, which have been summarized in Table 2 (142-151). These integrative resources will favor researchers to outline the landscape of EVs in cancer progression and identify relevant biomarkers more quickly and more accurately.

Integrating EVs-derived biomarkers with $\mathrm{ML}$ algorithms to analyze patterns in massive data sources such as gene expression, protein expression, or digital pathology data may obtain a higher diagnostic efficacy of the diagnosis. Chen et al. profiled four surface biomarkers including HER2, GPC-1, EpCAM, and EGFR from serum-derived EVs through DNA points accumulation for imaging in nanoscale topography. They implemented an integrated platform combining EVs identification with quantitative analysis and accurately differentiated pancreatic cancer and breast cancer from unknown samples (152). Additionally, advanced techniques such as microfluidic make it possible to separate EVs on a single chip. In a previous study, Ko et al. developed a multichannel microfluidic platform combining with ML algorithms that specifically isolated EVs from clinical plasma samples, quantitatively detected the RNA profile inside of EVs, and distinguished pancreatic cancer patients with healthy controls (153). They subsequently exploited another workflow that integrated a magnetic capture system with RNA sequencing and ML algorithms. This system purified a subpopulation of EVs and identified a panel of 11 miRNAs from EVs which could classify distinct cancer states in a transgenic mouse model (154). Thus, it is also a feasible strategy to combine upstream isolation methods with downstream ML algorithms to realize the development of "on-a-chip" platform for systemically purification and determination of EVs-derived biomarkers.

Moreover, AI approaches promises to make great strides in almost all stage of drug discovery, including target validation, biomarker identification, and analysis of clinical trial information (155). Since the drug data sets are becoming dynamic, heterogeneous and large scale, state-of-the-art AI approaches such as deep learning and innovative modeling methods provide new answers to efficacy and safety evaluations of drug candidates based on big data modeling and analysis (156). Donner et al. reported a novel method for computational drug repositioning by taking advantage of neural network. They revealed previously unnoticed functional relationships between different compounds based on denoise gene expression data rather than structural similarity (157). Hence AI approaches can build bridges between abundant data sources from high-throughput experiments with gene expression profiles and massive drug candidates. The information of EVs content is also increasingly rich in data. Meanwhile the downstream effects of EVs in cancer progression are non-linear. It is reasonable to assume that the ability of AI

TABLE 2 | EVs related online databases.

\begin{tabular}{|c|c|c|c|c|}
\hline Database & Publish date & Overview & Update date & References \\
\hline EVmiRNA & 2019 & $\begin{array}{l}\text { Comprehensive miRNA expression profiles in } 462 \text { EVs small } \\
\text { RNA-sequencing datasets from } 17 \text { tissues/diseases }\end{array}$ & 2019 & $(142)$ \\
\hline EVpedia & 2013 & $\begin{array}{l}\text { High-throughput datasets of EVs components (proteins, RNAs, and lipids) } \\
\text { from prokaryotic and eukaryotic EVs }\end{array}$ & 2013 & $(143)$ \\
\hline EV-TRACK & 2017 & Experimental parameters of EV-related studies & 2019 & $(144)$ \\
\hline ExoCarta & 2009 & $\begin{array}{l}\text { Identified contents (protein, mRNA, miRNA, and lipids) of exosomes in } \\
\text { multiple organisms from } 286 \text { studies }\end{array}$ & 2016 & $(145)$ \\
\hline exoRBase & 2018 & $\begin{array}{l}\text { Exosomal RNA (circRNA, IncRNA, and mRNA) derived from } \\
\text { RNA-sequencing data analyses of human blood }\end{array}$ & 2019 & $(146)$ \\
\hline $\begin{array}{l}\text { Exosome Gene Ontology } \\
\text { Annotation Initiative }\end{array}$ & 2015 & GO annotations of human exosomal proteins & 2015 & $(147)$ \\
\hline Plasma Proteome Database & 2014 & Annotation of 318 identified proteins of EVs from plasma & 2014 & $(148)$ \\
\hline $\begin{array}{l}\text { Urinary Exosome Protein } \\
\text { Database }\end{array}$ & 2004 & $\begin{array}{l}\text { Mass spectrometry data of } 1,160 \text { proteins derived from urinary exosomes } \\
\text { isolated from healthy human volunteers }\end{array}$ & 2009 & $(149,150)$ \\
\hline Vesiclepedia & 2012 & $\begin{array}{l}\text { Compendium of molecular data (lipid, RNA, and protein) identified in } \\
\text { different classes of EVs from 1,254 studies }\end{array}$ & 2019 & $(151)$ \\
\hline
\end{tabular}


to mining valuable information presents new opportunities for novel target identification and validation for EVs-based anticancer therapies. Therapeutic Target Database (TTD, http://db. idrblab.org/ttd/) has been established to integrate information of early drug candidates and therapeutic targets that contain expanded knowledge of target regulators such as miRNAs, transcription factors and other interacting proteins (158). Database with molecular information about drugs such as DrugBank (https://www.drugbank.ca/) include comprehensive data of the influence of hundreds drugs on metabolite levels, gene expression levels and protein expression levels, enabling us to find more connections of EVs content changes with drugs (159). Altogether, these important approaches may provide novel research tools to fundamental studies of EVs biology and translational studies of EVs-based therapies. Clearly, more work is need to be deployed in this scenario to figure out the completed mechanisms of EVs biogenesis, secretion and uptake, which may reward us valuable drug targets by using advanced AI approaches.

\section{PROSPECTS}

EVs are attracting increasing attention in cancer research due to its various roles in intracellular communication during cancer progression. However, RCC is relative unnoticed in this research hotspot compared with other cancer types. In this review, we recapitulated the roles and clinical implications of EVs in RCC. Diverse bioactive molecules carried by EVs regulate almost all processes of RCC, such as tumorigenesis, metastasis, immunosuppression, and drug resistance. Due to the unique function of kidney in urinary system, both blood and urine are valuable biofluids with abundant EVs, which are readily accessible sources for biomarkers discovery. Moreover,

\section{REFERENCES}

1. Shuch B, Amin A, Armstrong AJ, Eble JN, Ficarra V, Lopez-Beltran A, et al. Understanding pathologic variants of renal cell carcinoma: distilling therapeutic opportunities from biologic complexity. Eur Urol. (2015) 67:8597. doi: 10.1016/j.eururo.2014.04.029

2. Bray F, Ferlay J, Soerjomataram I, Siegel RL, Torre LA, Jemal A. Global cancer statistics 2018: GLOBOCAN estimates of incidence and mortality worldwide for 36 cancers in 185 countries. CA Cancer J Clin. (2018) 68:394-424. doi: $10.3322 /$ caac. 21492

3. Siegel RL, Miller KD, Jemal A. Cancer statistics, 2020. CA Cancer J Clin. (2020) 70:7-30. doi: 10.3322/caac.21590

4. Surveillance, Epidemiology, End Results Program. SEER Stat Fact Sheets: Kidney and Renal Pelvis Cancer. Bethesda, MD: National Cancer Institute. Available online at: https://seer.cancer.gov/statfacts/html/kidrp. html (accessed December 20, 2019).

5. Choueiri TK, Motzer RJ. Systemic therapy for metastatic renal-cell carcinoma. N Engl J Med. (2017) 376:354-66. doi: 10.1056/NEJMra1601333

6. Capitanio U, Montorsi F. Renal cancer. Lancet. (2016) 387:894-906. doi: 10.1016/S0140-6736(15)00046-X

7. Bhatt JR, Finelli A. Landmarks in the diagnosis and treatment of renal cell carcinoma. Nat Rev Urol. (2014) 11:517-25. doi: 10.1038/nrurol.2014.194

8. Koul H, Huh JS, Rove KO, Crompton L, Koul S, Meacham RB, et al. Molecular aspects of renal cell carcinoma: a review. Am J Cancer Res. (2011) 1:240-54. multiple potential applications can be developed to provide novel strategies for diagnosis and treatment of RCC, including but not limited to EVs-based cancer vaccine, in vivo imaging technique, targeted drug delivery system, and drug discovery. But it is noteworthy the detailed mechanisms and effects of EVs on RCC progression are still to be further clarified. The gaps between digital analysis and experimental validation are still need to be solved. Meantime there are still a variety of challenges for the clinical use of EVs in RCC. Standard operating procedure for EVs isolation, quantification, and analysis are still deficiency, especially for biofluids sample. The stability and the unknown side effects of EVs-based therapy must to be considered and assessed. Moreover, High-quality data sets are required in terms of the AI-aided drug target discovery based on EVs. Taken together, extensive work need to be launched to make a better understanding of roles of EVs in RCC progression and make the potential clinical utilities for EVs in RCC therapies come true.

\section{AUTHOR CONTRIBUTIONS}

ZQ was a major contributor in searching the literature and writing the manuscript. QX and HH reviewed the manuscript and provided significant revisions. $\mathrm{LY}$ and $\mathrm{SZ}$ gave critical advice and guidance throughout the whole process of this study. All the authors read and approved the final manuscript.

\section{FUNDING}

This project was supported by the National Key R\&D Program of China (2017YFE0102200), NSFC (81773817) and the Leading Talent of Ten Thousand Plan-National High-Level Talents Special Support Plan.
9. Kumbla RA, Figlin RA, Posadas EM. Recent advances in the medical treatment of recurrent or metastatic renal cell cancer. Drugs. (2017) 77:1728. doi: 10.1007/s40265-016-0665-1

10. van Niel G, D'Angelo G, Raposo G. Shedding light on the cell biology of extracellular vesicles. Nat Rev Mol Cell Biol. (2018) 19:213-28. doi: 10.1038/nrm.2017.125

11. Tkach M, Thery C. Communication by extracellular vesicles: where we are and where we need to go. Cell. (2016) 164:1226-32. doi: 10.1016/j.cell.2016.01.043

12. Kalluri R. The biology and function of exosomes in cancer. J Clin Invest. (2016) 126:1208-15. doi: 10.1172/JCI81135

13. He CJ, Zheng S, Luo Y, Wang B. Exosome theranostics: biology and translational medicine. Theranostics. (2018) 8:237-55. doi: 10.7150/thno.21945

14. Vader P, Breakefield XO, Wood MJA. Extracellular vesicles: emerging targets for cancer therapy. Trends Mol Med. (2014) 20:385-93. doi: 10.1016/j.molmed.2014.03.002

15. Nawaz M, Camussi G, Valadi H, Nazarenko I, Ekstrom K, Wang XQ, et al. The emerging role of extracellular vesicles as biomarkers for urogenital cancers. Nat Rev Urol. (2014) 11:688-701. doi: 10.1038/nrurol.2014.301

16. Franzen CA, Blackwell RH, Foreman KE, Kuo PC, Flanigan RC, Gupta GN. Urinary exosomes: the potential for biomarker utility, intercellular signaling and therapeutics in urological malignancy. J Urol. (2016) 195:1331-9. doi: 10.1016/j.juro.201 5.08 .115 
17. Junker K, Heinzelmann J, Beckham C, Ochiya T, Jenster G. Extracellular vesicles and their role in urologic malignancies. Euro Urol. (2016) 70:323-31. doi: 10.1016/j.eururo.2016.02.046

18. Merchant ML, Rood IM, Deegens JKJ, Klein JB. Isolation and characterization of urinary extracellular vesicles: implications for biomarker discovery. Nat Rev Nephrol. (2017) 13:731-49. doi: 10.1038/nrneph.2017.148

19. Panfoli I. Cancer exosomes in urine: a promising biomarker source. Transl Cancer Res. (2017) 6:S1389-93. doi: 10.21037/tcr.2017.10.17

20. Urabe F, Kosaka N, Kimura T, Egawa S, Ochiya T. Extracellular vesicles: toward a clinical application in urological cancer treatment. Int J Urol. (2018) 25:533-43. doi: 10.1111/iju.13594

21. Gai C, Pomatto MAC, Grange C, Deregibus MC, Camussi G. Extracellular vesicles in onco-nephrology. Exp Mol Med. (2019) 51:1-8. doi: 10.1038/s12276-019-0213-7

22. Grange C, Brossa A, Bussolati B. Extracellular vesicles and carried miRNAs in the progression of renal cell carcinoma. Int J Mol Sci. (2019) 20:1832. doi: 10.3390/ijms20081832

23. Di Vizio D, Kim J, Hager MH, Morello M, Yang W, Lafargue CJ, et al. Oncosome formation in prostate cancer: association with a region of frequent chromosomal deletion in metastatic disease. Cancer Res. (2009) 69:5601-9. doi: 10.1158/0008-5472.CAN-08-3860

24. Tricarico C, Clancy J, D'Souza-Schorey C. Biology and biogenesis of shed microvesicles. Small GTPases. (2017) 8:220-32. doi: $10.1080 / 21541248.2016 .1215283$

25. Colombo M, Raposo G, Thery C. Biogenesis, secretion, and intercellular interactions of exosomes and other extracellular vesicles. Annu Rev Cell Dev Biol. (2014) 30:255-89. doi: 10.1146/annurev-cellbio-101512-122326

26. Stenmark H. Rab GTPases as coordinators of vesicle traffic. Nat Rev Mol Cell Biol. (2009) 10:513-25. doi: 10.1038/nrm2728

27. Kowal J, Tkach M, Thery C. Biogenesis and secretion of exosomes. Curr Opin Cell Biol. (2014) 29:116-25. doi: 10.1016/j.ceb.2014.05.004

28. Jahn R, Scheller RH. SNAREs: engines for membrane fusion. Nat Rev Mol Cell Biol. (2006) 7:631-43. doi: 10.1038/nrm2002

29. Savina A, Fader CM, Damiani MT, Colombo MI. Rab11 promotes docking and fusion of multivesicular bodies in a calcium-dependent manner. Traffic. (2005) 6:131-43. doi: 10.1111/j.1600-0854.2004.00257.x

30. Faure J, Lachenal G, Court M, Hirrlinger J, Chatellard-Causse C, Blot B, et al. Exosomes are released by cultured cortical neurones. Mol Cell Neurosci. (2006) 31:642-8. doi: 10.1016/j.mcn.2005.12.003

31. Horibe S, Tanahashi T, Kawauchi S, Murakami Y, Rikitake Y. Mechanism of recipient cell-dependent differences in exosome uptake. BMC Cancer. (2018) 18:47. doi: 10.1186/s12885-017-3958-1

32. Nazarenko I, Rana S, Baumann A, McAlear J, Hellwig A, Trendelenburg M, et al. Cell surface tetraspanin Tspan 8 contributes to molecular pathways of exosome-induced endothelial cell activation. Cancer Res. (2010) 70:1668-78. doi: 10.1158/0008-5472.CAN-09-2470

33. Hoshino A, Costa-Silva B, Shen TL, Rodrigues G, Hashimoto A, Tesic Mark $\mathrm{M}$, et al. Tumour exosome integrins determine organotropic metastasis. Nature. (2015) 527:329-35. doi: 10.1038/nature15756

34. Deatherage BL, Cookson BT. Membrane vesicle release in bacteria, eukaryotes, and archaea: a conserved yet underappreciated aspect of microbial life. Infect Immun. (2012) 80:1948-57. doi: 10.1128/IAI.06014-11

35. Wang Z, Chen JQ, Liu JL, Tian L. Exosomes in tumor microenvironment: novel transporters and biomarkers. J Transl Med. (2016) 14:297. doi: 10.1186/s12967-016-1056-9

36. Mathieu M, Martin-Jaular L, Lavieu G, Thery C. Specificities of secretion and uptake of exosomes and other extracellular vesicles for cell-to-cell communication. Nat Cell Biol. (2019) 21:9-17. doi: 10.1038/s41556-018-0250-9

37. Xu R, Rai A, Chen M, Suwakulsiri W, Greening DW, Simpson RJ. Extracellular vesicles in cancer: implications for future improvements in cancer care. Nat Rev Clin Oncol. (2018) 15:617-38. doi: 10.1038/s41571-018-0036-9

38. Ratajczak J, Miekus K, Kucia M, Zhang J, Reca R, Dvorak P, et al. Embryonic stem cell-derived microvesicles reprogram hematopoietic progenitors: evidence for horizontal transfer of mRNA and protein delivery. Leukemia. (2006) 20:847-56. doi: 10.1038/sj.leu.2404132
39. Valadi H, Ekstrom K, Bossios A, Sjostrand M, Lee JJ, Lotvall JO. Exosomemediated transfer of mRNAs and microRNAs is a novel mechanism of genetic exchange between cells. Nat Cell Biol. (2007) 9:654-72. doi: $10.1038 /$ ncb 1596

40. Skog J, Wurdinger T, van Rijn S, Meijer DH, Gainche L, Sena-Esteves M, et al. Glioblastoma microvesicles transport RNA and proteins that promote tumour growth and provide diagnostic biomarkers. Nat Cell Biol. (2008) 10:1470-9. doi: 10.1038/ncb1800

41. Hinger SA, Cha DJ, Franklin JL, Higginbotham JN, Dou YC, Ping J, et al. Diverse long RNAs are differentially sorted into extracellular vesicles secreted by colorectal cancer cells. Cell Rep. (2018) 25:715-25.e4. doi: 10.1016/j.celrep.2018.09.054

42. Chen F, Chen JN, Yang LB, Liu J, Zhang XQ, Zhang Y, et al. Extracellular vesicle-packaged HIF-1 $\alpha$-stabilizing lncRNA from tumourassociated macrophages regulates aerobic glycolysis of breast cancer cells. Nat Cell Biol. (2019) 21:498-510. doi: 10.1038/s41556-019-0299-0

43. Li Y, Zheng QP, Bao CY, Li SY, Guo WJ, Zhao J, et al. Circular RNA is enriched and stable in exosomes: a promising biomarker for cancer diagnosis. Cell Res. (2015) 25:981-4. doi: 10.1038/cr.2015.82

44. Bai H, Lei K, Huang F, Jiang Z, Zhou X. Exo-circRNAs: a new paradigm for anticancer therapy. Mol Cancer. (2019) 18:56. doi: 10.1186/s12943-019-0986-2

45. Huang XY, Yuan TZ, Tschannen M, Sun ZF, Jacob H, Du MJ, et al. Characterization of human plasma-derived exosomal RNAs by deep sequencing. BMC Genomics. (2013) 14:319. doi: 10.1186/1471-2164-14-319

46. Kalluri R, LeBleu VS. Discovery of double-stranded genomic DNA in circulating exosomes. Cold Spring Harb Symp Quant Biol. (2016) 81:275-80. doi: $10.1101 /$ sqb.2016.81.030932

47. Takahashi A, Okada R, Nagao K, Kawamata Y, Hanyu A, Yoshimoto S, et al. Exosomes maintain cellular homeostasis by excreting harmful DNA from cells. Nat Commun. (2017) 8:15287. doi: 10.1038/ncomms15287

48. Balaj L, Lessard R, Dai L, Cho YJ, Pomeroy SL, Breakefield XO, et al. Tumour microvesicles contain retrotransposon elements and amplified oncogene sequences. Nat Commun. (2011) 2:180. doi: 10.1038/ncomms1180

49. Thakur BK, Zhang H, Becker A, Matei I, Huang Y, Costa-Silva B, et al. Double-stranded DNA in exosomes: a novel biomarker in cancer detection. Cell Res. (2014) 24:766-9. doi: 10.1038/cr.2014.44

50. Kawamura Y, Yamamoto Y, Sato T-A, Ochiya T. Extracellular vesicles as trans-genomic agents: emerging roles in disease and evolution. Cancer Sci. (2017) 108:824-30. doi: 10.1111/cas.13222

51. Carvalho J, Oliveira C. Extracellular vesicles - powerful markers of cancer evolution. Front Immunol. (2014) 5:685. doi: 10.3389/fimmu.2014.00685

52. Raposo G, Stoorvogel W. Extracellular vesicles: exosomes, microvesicles, and friends. J Cell Biol. (2013) 200:373-83. doi: 10.1083/jcb.201211138

53. Charrin S, Jouannet S, Boucheix C, Rubinstein E. Tetraspanins at a glance. $J$ Cell Sci. (2014) 127:3641-8. doi: 10.1242/jcs.154906

54. Thery C, Zitvogel L, Amigorena S. Exosomes: composition, biogenesis and function. Nat Rev Immunol. (2002) 2:569-79. doi: 10.1038/nri855

55. Console L, Scalise M, Tonazzi A, Giangregorio N, Indiveri C. Characterization of exosomal SLC22A5 (OCTN2) carnitine transporter. Sci Rep. (2018) 8:3758. doi: 10.1038/s41598-018-22170-7

56. Taylor J, Bebawy M. Proteins regulating microvesicle biogenesis and multidrug resistance in cancer. Proteomics. (2019) 19:e1800165. doi: 10.1002/pmic.201800165

57. Gerth K, Kodidela S, Mahon M, Haque S, Verma N, Kumar S. Circulating extracellular vesicles containing xenobiotic metabolizing CYP enzymes and their potential roles in extrahepatic cells via cell-cell interactions. Int $\mathrm{J} \mathrm{Mol}$ Sci. (2019) 20:6178. doi: 10.3390/ijms20246178

58. Li P, Kaslan M, Lee SH, Yao J, Gao Z. Progress in exosome isolation techniques. Theranostics. (2017) 7:789-804. doi: 10.7150/thno.18133

59. Tian Y, Gong M, Hu Y, Liu H, Zhang W, Zhang M, et al. Quality and efficiency assessment of six extracellular vesicle isolation methods by nano-flow cytometry. J Extracell Vesicles. (2020) 9:1697028. doi: 10.1080/20013078.2019.1697028

60. Guo SC, Tao SC, Dawn H. Microfluidics-based on-a-chip systems for isolating and analysing extracellular vesicles. J Extracell Vesicles. (2018) 7:1508271. doi: 10.1080/20013078.2018.1508271 
61. Gardiner C, Di Vizio D, Sahoo S, Thery C, Witwer KW, Wauben M, et al. Techniques used for the isolation and characterization of extracellular vesicles: results of a worldwide survey. J Extracell Vesicles. (2016) 5:32945. doi: 10.3402/jev.v5.32945

62. Thery C, Witwer KW, Aikawa E, Alcaraz MJ, Anderson JD, Andriantsitohaina R, et al. Minimal information for studies of extracellular vesicles 2018 (MISEV2018): a position statement of the international society for extracellular vesicles and update of the MISEV2014 guidelines. J Extracell Vesicles. (2018) 7:1535750. doi: 10.1080/20013078.2018.1461450

63. Maacha S, Bhat AA, Jimenez L, Raza A, Haris M, Uddin S, et al. Extracellular vesicles-mediated intercellular communication: roles in the tumor microenvironment and anti-cancer drug resistance. Mol Cancer. (2019) 18:55. doi: 10.1186/s12943-019-0965-7

64. Maia J, Caja S, Moraes MCS, Couto N, Costa-Silva B. Exosome-based cell-cell communication in the tumor microenvironment. Front Cell Dev Biol. (2018) 6:18. doi: 10.3389/fcell.2018.00018

65. Jiang XL, Zhang Y, Tan B, Luo CL, Wu XH. Renal tumor-derived exosomes inhibit hepaCAM expression of renal carcinoma cells in a p-AKT-dependent manner. Neoplasma. (2014) 61:416-23. doi: 10.4149/neo_2014_051

66. Du T, Ju G, Wu S, Cheng Z, Cheng J, Zou X, et al. Microvesicles derived from human Wharton's Jelly mesenchymal stem cells promote human renal cancer cell growth and aggressiveness through induction of hepatocyte growth factor. PLoS ONE. (2014) 9:e96836. doi: 10.1371/journal.pone.0096836

67. Song S, Long M, Yu G, Cheng Y, Yang Q, Liu J, et al. Urinary exosome miR-30c-5p as a biomarker of clear cell renal cell carcinoma that inhibits progression by targeting HSPA5. J Cell Mol Med. (2019) 23:6755-65. doi: $10.1111 / \mathrm{jcmm} .14553$

68. Chamie K, Klöpfer P, Bevan P, Störkel S, Said J, Fall B, et al. Carbonic anhydrase-IX score is a novel biomarker that predicts recurrence and survival for high-risk, nonmetastatic renal cell carcinoma: data from the phase III ARISER clinical trial. Urol Oncol. (2015) 33:204.e25-33. doi: 10.1016/j.urolonc.2015.02.013

69. Horie K, Kawakami K, Fujita Y, Sugaya M, Kameyama K, Mizutani K, et al. Exosomes expressing carbonic anhydrase 9 promote angiogenesis. Biochem Biophys Res Commun. (2017) 492:356-61. doi: 10.1016/j.bbrc.2017.08.107

70. Parolini I, Federici C, Raggi C, Lugini L, Palleschi S, de Milito A, et al. Microenvironmental $\mathrm{pH}$ is a key factor for exosome traffic in tumor cells. J Biol Chem. (2009) 284:34211-22. doi: 10.1074/jbc.M109.041152

71. Guo J, Jayaprakash P, Dan J, Wise P, Jang GB, Liang C, et al. PRAS40 connects microenvironmental stress signaling to exosome-mediated secretion. $\mathrm{Mol}$ Cell Biol. (2017) 37:e00171-17. doi: 10.1128/MCB.00171-17

72. Wang X, Wang T, Chen C, Wu Z, Bai P, Li S, et al. Serum exosomal miR-210 as a potential biomarker for clear cell renal cell carcinoma. J Cell Biochem. (2019) 120:1492-502. doi: 10.1002/jcb.27347

73. Jung KO, Jo H, Yu JH, Gambhir SS, Pratx G. Development and MPI tracking of novel hypoxia-targeted theranostic exosomes. Biomaterials. (2018) 177:139-48. doi: 10.1016/j.biomaterials.2018.05.048

74. Becker A, Thakur BK, Weiss JM, Kim HS, Peinado H, Lyden D. Extracellular vesicles in cancer: cell-to-cell mediators of metastasis. Cancer Cell. (2016) 30:836-48. doi: 10.1016/j.ccell.2016.10.009

75. Chen G, Zhang Y, Wu XH. 786-O renal cancer cell line-derived exosomes promote 786-O cell migration and invasion in vitro. Oncol Lett. (2014) 7:1576-80. doi: 10.3892/ol.2014.1962

76. Grange C, Tapparo M, Collino F, Vitillo L, Damasco C, Deregibus MC, et al. Microvesicles released from human renal cancer stem cells stimulate angiogenesis and formation of lung premetastatic niche. Cancer Res. (2011) 71:5346-56. doi: 10.1158/0008-5472.CAN-11-0241

77. Lindoso RS, Collino F, Camussi G. Extracellular vesicles derived from renal cancer stem cells induce a pro-tumorigenic phenotype in mesenchymal stromal cells. Oncotarget. (2015) 6:7959-69. doi: 10.18632/oncotarget.3503

78. Wang L, Yang G, Zhao D, Wang J, Bai Y, Peng Q, et al. CD103-positive CSC exosome promotes EMT of clear cell renal cell carcinoma: role of remote miR-19b-3p. Mol Cancer. (2019) 18:86. doi: 10.1186/s12943-019-0997-z

79. Rana S, Yue S, Stadel D, Zoller M. Toward tailored exosomes: the exosomal tetraspanin web contributes to target cell selection. Int J Biochem Cell Biol. (2012) 44:1574-84. doi: 10.1016/j.biocel.2012.06.018

80. Singh A, Fedele C, Lu H, Nevalainen MT, Keen JH, Languino LR. Exosomemediated transfer of $\alpha_{\mathrm{v}} \beta_{3}$ integrin from tumorigenic to nontumorigenic cells promotes a migratory phenotype. Mol Cancer Res. (2016) 14:1136-46 doi: 10.1158/1541-7786.MCR-16-0058

81. Thery C, Ostrowski M, Segura E. Membrane vesicles as conveyors of immune responses. Nat Rev Immunol. (2009) 9:581-93. doi: 10.1038/nri2567

82. Grange C, Tapparo M, Tritta S, Deregibus MC, Battaglia A, Gontero P, et al. Role of HLA-G and extracellular vesicles in renal cancer stem cell-induced inhibition of dendritic cell differentiation. BMC Cancer. (2015) 15:1009. doi: 10.1186/s12885-015-2025-Z

83. Kochan G, Escors D, Breckpot K, Guerrero-Setas D. Role of non-classical MHC class I molecules in cancer immunosuppression. Oncoimmunol. (2013) 2:e26491. doi: 10.4161/onci.26491

84. Yang L, Wu X, Wang D, Luo C, Chen L. Renal carcinoma cell-derived exosomes induce human immortalized line of Jurkat T lymphocyte apoptosis in vitro. Urol Int. (2013) 91:363-9. doi: 10.1159/000348747

85. Xia Y, Zhang Q, Zhen Q, Zhao Y, Liu N, Li T, et al. Negative regulation of tumor-infiltrating NK cell in clear cell renal cell carcinoma patients through the exosomal pathway. Oncotarget. (2017) 8:37783-95. doi: 10.18632/oncotarget.16354

86. Diao JJ, Yang X, Song XD, Chen SY, He YF, Wang QS, et al. Exosomal Hsp70 mediates immunosuppressive activity of the myeloidderived suppressor cells via phosphorylation of stat3. Med Oncol. (2015) 32:453. doi: 10.1007/s12032-014-0453-2

87. Zou WP, Wolchok JD, Chen LP. PD-L1 (B7-H1) and PD-1 pathway blockade for cancer therapy: mechanisms, response biomarkers, and combinations. Sci Transl Med. (2016) 8:328rv4. doi: 10.1126/scitranslmed.aad7118

88. Page DB, Postow MA, Callahan MK, Allison JP, Wolchok JD. Immune modulation in cancer with antibodies. Annu Rev Med. (2014) 65:185-202. doi: 10.1146/annurev-med-092012-112807

89. Theodoraki MN, Yerneni SS, Hoffmann TK, Gooding WE, Whiteside TL. Clinical significance of PD-L1 $(+)$ exosomes in plasma of head and neck cancer patients. Clin Cancer Res. (2018) 24:896-905. doi: 10.1158/1078-0432.CCR-17-2664

90. Ricklefs FL, Alayo Q, Krenzlin H, Mahmoud AB, Speranza MC, Nakashima $\mathrm{H}$, et al. Immune evasion mediated by PD-L1 on glioblastoma-derived extracellular vesicles. Sci Adv. (2018) 4:aar2766. doi: 10.1126/sciadv.aar2766

91. Yang Y, Li CW, Chan LC, Wei YK, Hsu JM, Xia WY, et al. Exosomal PD-L1 harbors active defense function to suppress $\mathrm{T}$ cell killing of breast cancer cells and promote tumor growth. Cell Res. (2018) 28:862-4. doi: 10.1038/s41422-018-0060-4

92. Chen G, Huang AC, Zhang W, Zhang G, Wu M, Xu W, et al. Exosomal $\mathrm{PD}-\mathrm{L} 1$ contributes to immunosuppression and is associated with anti-PD-1 response. Nature. (2018) 560:382-6. doi: 10.1038/s41586-018-0392-8

93. Song Y, Wu L, Yang C. Exosomal PD-L1: an effective liquid biopsy target to predict immunotherapy response. Natl Sci Rev. (2019) 6:1103-4. doi: $10.1093 / \mathrm{nsr} / \mathrm{nwy} 154$

94. Xie F, Xu M, Lu J, Mao L, Wang S. The role of exosomal PD-L1 in tumor progression and immunotherapy. Mol Cancer. (2019) 18:146. doi: 10.1186/s12943-019-1074-3

95. Poggio M, Hu TY, Pai CC, Chu B, Belair CD, Chang A, et al. Suppression of exosomal PD-L1 induces systemic anti-tumor immunity and memory. Cell. (2019) 177:414-27. doi: 10.1016/j.cell.201 9.02.016

96. Huang M, Yang J, Wang T, Song J, Xia J, Wu L, et al. Homogeneous, low-volume, efficient and sensitive quantitation of circulating exosomal PD-L1 for cancer diagnosis and immunotherapy response prediction. Angew Chem Int Ed Engl. (2020) 59:4800-5. doi: 10.1002/ange.2019 16039

97. Pang Y, Shi J, Yang X, Wang C, Sun Z, Xiao R. Personalized detection of circling exosomal PD-L1 based on $\mathrm{Fe}_{3} \mathrm{O}_{4} @ \mathrm{TiO}_{2}$ isolation and SERS immunoassay. Biosens Bioelectron. (2020) 148:111800. doi: 10.1016/j.bios.2019.111800

98. Sousa D, Lima RT, Vasconcelos MH. Intercellular transfer of cancer drug resistance traits by extracellular vesicles. Trends Mol Med. (2015) 21:595-608. doi: 10.1016/j.molmed.2015.08.002

99. Corcoran C, Rani S, O’Brien K, O’Neill A, Prencipe M, Sheikh R, et al. Docetaxel-resistance in prostate cancer: evaluating associated phenotypic changes and potential for resistance transfer via exosomes. PLoS ONE. (2012) 7:e50999. doi: 10.1371/journal.pone.0050999 
100. Yin J, Sun W, Li F, Hong J, Li X, Zhou Y, et al. VARIDT 1.0: variability of drug transporter database. Nucleic Acids Res. (2020) 48:D1042-50. doi: $10.1093 /$ nar/gkz878

101. Motzer RJ, Hutson TE, Tomczak P, Michaelson MD, Bukowski RM, Rixe O, et al. Sunitinib versus interferon alfa in metastatic renal-cell carcinoma. $N$ Eng J Med. (2007) 356:115-24. doi: 10.1056/NEJMoa065044

102. Rini BI, Atkins MB. Resistance to targeted therapy in renal-cell carcinoma. Lancet Oncol. (2009) 10:992-1000. doi: 10.1016/S1470-2045(09)70240-2

103. Qu L, Ding J, Chen C, Wu ZJ, Liu B, Gao Y, et al. Exosometransmitted lncARSR promotes sunitinib resistance in renal cancer by acting as a competing endogenous RNA. Cancer Cell. (2016) 29:653-68. doi: 10.1016/j.ccell.2016.03.004

104. Tang Z, Li D, Hou S, Zhu X. The cancer exosomes: clinical implications, applications and challenges. Int $J$ Cancer. (2020) 11:2946-59. doi: $10.1002 / \mathrm{ijc} .32762$

105. Zhao A, Li GR, Peoc'h M, Genin C, Gigante M. Serum miR-210 as a novel biomarker for molecular diagnosis of clear cell renal cell carcinoma. Exp Mol Pathol. (2013) 94:115-20. doi: 10.1016/j.yexmp.2012.10.005

106. Zhang W, Ni M, Su Y, Wang H, Zhu S, Zhao A, et al. MicroRNAs in serum exosomes as potential biomarkers in clear-cell renal cell carcinoma. Eur Urol Focus. (2018) 4:412-9. doi: 10.1016/j.euf.2016.09.007

107. Cheng TT, Wang LN, Li YY, Huang C, Zeng LX, Yang J. Differential microRNA expression in renal cell carcinoma. Oncol Lett. (2013) 6:769-76. doi: 10.3892/ol.2013.1460

108. Chen X, Lou N, Ruan A, Qiu B, Yan Y, Wang X, et al. miR-224/miR-141 ratio as a novel diagnostic biomarker in renal cell carcinoma. Oncol Lett. (2018) 16:1666-74. doi: 10.3892/ol.2018.8874

109. Fujii N, Hirata H, Ueno K, Mori J, Oka S, Shimizu K, et al. Extracellular miR224 as a prognostic marker for clear cell renal cell carcinoma. Oncotarget. (2017) 8:109877-88. doi: 10.18632/oncotarget.22436

110. Du MJ, Giridhar KV, Tian YJ, Tschannen MR, Zhu J, Huang CC, et al. Plasma exosomal miRNAs-based prognosis in metastatic kidney cancer. Oncotarget. (2017) 8:63703-14. doi: 10.18632/oncotarget.19476

111. Butz H, Nofech-Mozes R, Ding Q, Khella HWZ, Szabó PM, Jewett M, et al. Exosomal microRNAs are diagnostic biomarkers and can mediate cellcell communication in renal cell carcinoma. Eur Urol Focus. (2016) 2:210-8. doi: 10.1016/j.euf.2015.11.006

112. Crentsil VC, Liu H, Sellitti DF. Comparison of exosomal microRNAs secreted by $786-\mathrm{O}$ clear cell renal carcinoma cells and HK-2 proximal tubule-derived cells in culture identifies microRNA-205 as a potential biomarker of clear cell renal carcinoma. Oncol Lett. (2018) 16:1285-90. doi: 10.3892/ol.2018.8751

113. Liu Y, Zheng X, Yu Q, Wang H, Tan F, Zhu Q, et al. Epigenetic activation of the drug transporter OCT2 sensitizes renal cell carcinoma to oxaliplatin. Sci Transl Med. (2016) 8:348ra97. doi: 10.1126/scitranslmed. aaf3124

114. Chen L, Chen L, Qin Z, Lei J, Ye S, Zeng K, et al. Upregulation of miR-489-3p and miR-630 inhibits oxaliplatin uptake in renal cell carcinoma by targeting OCT2. Acta Pharm Sin B. (2019) 9:1008-20. doi: 10.1016/j.apsb.2019. 01.002

115. de Palma G, Sallustio F, Curci C, Galleggiante V, Rutigliano M, Serino $\mathrm{G}$, et al. The three-gene signature in urinary extracellular vesicles from patients with clear cell renal cell carcinoma. J Cancer. (2016) 7:1960-7. doi: $10.7150 /$ jca. 16123

116. Del Boccio P, Raimondo F, Pieragostino D, Morosi L, Cozzi G, Sacchetta P, et al. A hyphenated microLC-Q-TOF-MS platform for exosomal lipidomics investigations: application to RCC urinary exosomes. Electrophoresis. (2012) 33:689-96. doi: 10.1002/elps.201100375

117. Raimondo F, Morosi L, Corbetta S, Chinello C, Brambilla P, Della Mina P, et al. Differential protein profiling of renal cell carcinoma urinary exosomes. Mol Biosyst. (2013) 9:1220-33. doi: 10.1039/c3mb25582d

118. Jingushi K, Uemura M, Ohnishi N, Nakata W, Fujita K, Naito T, et al. Extracellular vesicles isolated from human renal cell carcinoma tissues disrupt vascular endothelial cell morphology via azurocidin. Int J Cancer. (2018) 142:607-17. doi: 10.1002/ijc.31080

119. Kamerkar S, LeBleu VS, Sugimoto H, Yang S, Ruivo CF, Melo SA, et al. Exosomes facilitate therapeutic targeting of oncogenic KRAS in pancreatic cancer. Nature. (2017) 546:498-503. doi: 10.1038/nature22341
120. Mendt M, Kamerkar S, Sugimoto H, McAndrews KM, Wu CC, Gagea M, et al. Generation and testing of clinical-grade exosomes for pancreatic cancer. JCI Insight. (2018) 3:e99263. doi: 10.1172/jci.insight.99263

121. Wiklander OPB, Brennan MÁ, Lötvall J, Breakefield XO, El Andaloussi S. Advances in therapeutic applications of extracellular vesicles. Sci Transl Med. (2019) 11:eaav8521. doi: 10.1126/scitranslmed.aav8521

122. Tian Y, Li S, Song J, Ji T, Zhu M, Anderson GJ, et al. A doxorubicin delivery platform using engineered natural membrane vesicle exosomes for targeted tumor therapy. Biomaterials. (2014) 35:2383-90. doi: 10.1016/j.biomaterials.2013.11.083

123. Wan Y, Wang L, Zhu C, Zheng Q, Wang G, Tong J, et al. Aptamer-conjugated extracellular nanovesicles for targeted drug delivery. Cancer Res. (2018) 78:798-808. doi: 10.1158/0008-5472.CAN-17-2880

124. Oosterwijk E, Ruiter DJ, Hoedemaeker PJ, Pauwels EK, Jonas U, Zwartendijk J, et al. Monoclonal antibody G250 recognizes a determinant present in renal-cell carcinoma and absent from normal kidney. Int J Cancer. (1986) 38:489-94. doi: 10.1002/ijc.2910380406

125. Zhang Y, Luo CL, He BC, Zhang JM, Cheng G, Wu XH. Exosomes derived from IL-12-anchored renal cancer cells increase induction of specific antitumor response in vitro: a novel vaccine for renal cell carcinoma. Int $J$ Oncol. (2010) 36:133-40. doi: 10.3892/ijo_00000484

126. van der Grein SG, Defourny KAY, Slot EFJ, Nolte-'t Hoen ENM. Intricate relationships between naked viruses and extracellular vesicles in the crosstalk between pathogen and host. Semin Immunopathol. (2018) 40:491-504. doi: 10.1007/s00281-018-0678-9

127. Zomer A, Maynard C, Verweij FJ, Kamermans A, Schafer R, Beerling E, et al. In vivo imaging reveals extracellular vesicle-mediated phenocopying of metastatic behavior. Cell. (2015) 161:1046-57. doi: 10.1016/j.cell.2015.04.042

128. Gangadaran P, Hong CM, Ahn BC. An update on in vivo imaging of extracellular vesicles as drug delivery vehicles. Front Pharmacol. (2018) 9:169. doi: 10.3389/fphar.2018.00169

129. Datta A, Kim H, McGee L, Johnson AE, Talwar S, Marugan J, et al. Highthroughput screening identified selective inhibitors of exosome biogenesis and secretion: a drug repurposing strategy for advanced cancer. Sci Rep. (2018) 8:8161. doi: 10.1038/s41598-018-26411-7

130. Catalano M, O'Driscoll L. Inhibiting extracellular vesicles formation and release: a review of EV inhibitors. J Extracell Vesicles. (2020) 9:1703244. doi: 10.1080/20013078.2019.1703244

131. Ortiz A, Gui J, Zahedi F, Yu P, Cho C, Bhattacharya S, et al. An interferondriven oxysterol-based defense against tumor-derived extracellular vesicles. Cancer Cell. (2019) 35:33-45.e6. doi: 10.1016/j.ccell.2018.12.001

132. Im E-J, Lee C-H, Moon P-G, Rangaswamy GG, Lee B, Lee JM, et al. Sulfisoxazole inhibits the secretion of small extracellular vesicles by targeting the endothelin receptor A. Nat Commun. (2019) 10:1387. doi: 10.1038/s41467-019-09387-4

133. Bi WL, Hosny A, Schabath MB, Giger ML, Birkbak NJ, Mehrtash A, et al. Artificial intelligence in cancer imaging: clinical challenges and applications. CA Cancer J Clin. (2019) 69:127-57. doi: 10.3322/caac.21552

134. Tabibu S, Vinod PK, Jawahar CV. Pan-renal cell carcinoma classification and survival prediction from histopathology images using deep learning. Sci Rep. (2019) 9:10509. doi: 10.1038/s41598-019-46718-3

135. Han S, Hwang SI, Lee HJ. The classification of renal cancer in 3-phase CT images using a deep learning method. J Digit Imaging. (2019) 32:638-43. doi: 10.1007/s10278-019-00230-2

136. Ito K, Ogawa Y, Yokota K, Matsumura S, Minamisawa T, Suga K, et al. Host cell prediction of exosomes using morphological features on solid surfaces analyzed by machine learning. J Phys Chem B. (2018) 122:6224-35. doi: 10.1021/acs.jpcb.8b01646

137. Gomez-de-Mariscal E, Maska M, Kotrbova A, Pospichalova V, Matula P, Munoz-Barrutia A. Deep-learning-based segmentation of small extracellular vesicles in transmission electron microscopy images. Sci Rep. (2019) 9:13211. doi: 10.1038/s41598-019-49431-3

138. Borgovan T, Crawford L, Nwizu C, Quesenberry P. Stem cells and extracellular vesicles: biological regulators of physiology and disease. Am J Physiol Cell Physiol. (2019) 317:C155-66. doi: 10.1152/ajpcell.000 17.2019

139. Won Y, Song HJ, Kang TW, Kim JJ, Han BD, Lee SW. Pattern analysis of serum proteome distinguishes renal cell carcinoma from 
other urologic diseases and healthy persons. Proteomics. (2003) 3:2310-6. doi: 10.1002/pmic.200300590

140. Zheng H, Ji J, Zhao L, Chen M, Shi A, Pan L, et al. Prediction and diagnosis of renal cell carcinoma using nuclear magnetic resonance-based serum metabolomics and self-organizing maps. Oncotarget. (2016) 7:59189-98. doi: 10.18632/oncotarget.10830

141. Gezsi A, Kovacs A, Visnovitz T, Buzas EI. Systems biology approaches to investigating the roles of extracellular vesicles in human diseases. Exp Mol Med. (2019) 51:1-11. doi: 10.1038/s12276-019-0226-2

142. Liu T, Zhang Q, Zhang J, Li C, Miao YR, Lei Q, et al. EVmiRNA: a database of miRNA profiling in extracellular vesicles. Nucleic Acids Res. (2019) 47:D89-93. doi: 10.1093/nar/gky985

143. Kim DK, Kang B, Kim OY, Choi DS, Lee J, Kim SR, et al. EVpedia: an integrated database of high-throughput data for systemic analyses of extracellular vesicles. J Extracell Vesicles. (2013) 2:20384. doi: 10.3402/jev.v2i0.20384

144. Consortium E-T, van Deun J, Mestdagh P, Agostinis P, Akay O, Anand S, et al. EV-TRACK: transparent reporting and centralizing knowledge in extracellular vesicle research. Nat Methods. (2017) 14:228-32. doi: 10.1038/nmeth.4185

145. Mathivanan S, Simpson RJ. ExoCarta: a compendium of exosomal proteins and RNA. Proteomics. (2009) 9:4997-5000. doi: 10.1002/pmic.200900351

146. Li S, Li Y, Chen B, Zhao J, Yu S, Tang Y, et al. exoRBase: a database of circRNA, lncRNA and mRNA in human blood exosomes. Nucleic Acids Res. (2018) 46:D106-12. doi: 10.1093/nar/gkx891

147. Huntley RP, Sawford T, Mutowo-Meullenet P, Shypitsyna A, Bonilla C, Martin MJ, et al. The GOA database: gene ontology annotation updates for 2015. Nucleic Acids Res. (2015) 43:D1057-63. doi: 10.1093/nar/ gku1113

148. Nanjappa V, Thomas JK, Marimuthu A, Muthusamy B, Radhakrishnan A, Sharma R, et al. Plasma proteome database as a resource for proteomics research: 2014 update. Nucleic Acids Res. (2014) 42:D959-D65. doi: 10.1093/nar/gkt1251

149. Pisitkun T, Shen RF, Knepper MA. Identification and proteomic profiling of exosomes in human urine. Proc Natl Acad Sci USA. (2004) 101:13368-73. doi: 10.1073/pnas.0403453101

150. Gonzales PA, Pisitkun T, Hoffert JD, Tchapyjnikov D, Star RA, Kleta $\mathrm{R}$, et al. Large-scale proteomics and phosphoproteomics of urinary exosomes. J Am Soc Nephrol. (2009) 20:363-79. doi: 10.1681/ASN.2008 040406

151. Kalra H, Simpson RJ, Ji H, Aikawa E, Altevogt P, Askenase P, et al. Vesiclepedia: a compendium for extracellular vesicles with continuous community annotation. PLoS Biol. (2012) 10:e1001450. doi: 10.1371/journal.pbio.1001450

152. Chen C, Zong S, Liu Y, Wang Z, Zhang Y, Chen B, et al. Profiling of exosomal biomarkers for accurate cancer identification: combining DNA-PAINT with machine-learning-based classification. Small. (2019) 15:e1901014. doi: 10.1002/smll.201901014

153. Ko J, Bhagwat N, Yee SS, Ortiz N, Sahmoud A, Black T, et al. Combining machine learning and nanofluidic technology to diagnose pancreatic cancer using exosomes. ACS Nano. (2017) 11:11182-93. doi: 10.1021/acsnano.7b05503

154. Ko J, Bhagwat N, Black T, Yee SS, Na YJ, Fisher S, et al. miRNA profiling of magnetic nanopore-isolated extracellular vesicles for the diagnosis of pancreatic cancer. Cancer Res. (2018) 78:3688-97. doi: 10.1158/0008-5472.CAN-17-3703

155. Vamathevan J, Clark D, Czodrowski P, Dunham I, Ferran E, Lee G, et al. Applications of machine learning in drug discovery and development. Nat Rev Drug Discov. (2019) 18:463-77. doi: 10.1038/s41573-019-0024-5

156. Zhu $H$. Big data and artificial intelligence modeling for drug discovery. Annu Rev Pharmacol Toxicol. (2020) 60:573-89. doi: 10.1146/annurev-pharmtox-010919-023324

157. Donner Y, Kazmierczak S, Fortney K. Drug repurposing using deep embeddings of gene expression profiles. Mol Pharma. (2018) 15:4314-25. doi: 10.1021/acs.molpharmaceut.8b00284

158. Wang Y, Zhang S, Li F, Zhou Y, Zhang Y, Wang Z, et al. Therapeutic target database 2020: enriched resource for facilitating research and early development of targeted therapeutics. Nucleic Acids Res. (2020) 48:D103141. doi: 10.1093/nar/gkz981

159. Wishart DS, Feunang YD, Guo AC, Lo EJ, Marcu A, Grant JR, et al. DrugBank 5.0: a major update to the drugBank database for 2018. Nucleic Acids Res. (2018) 46:D1074-82. doi: 10.1093/nar/gkx1037

Conflict of Interest: The authors declare that the research was conducted in the absence of any commercial or financial relationships that could be construed as a potential conflict of interest.

Copyright (c) $2020 \mathrm{Qin}, \mathrm{Xu}, \mathrm{Hu}, \mathrm{Yu}$ and Zeng. This is an open-access article distributed under the terms of the Creative Commons Attribution License (CC BY). The use, distribution or reproduction in other forums is permitted, provided the original author(s) and the copyright owner(s) are credited and that the original publication in this journal is cited, in accordance with accepted academic practice. No use, distribution or reproduction is permitted which does not comply with these terms. 